\title{
Desinformação, desinfodemia e letramento midiático e informacional - um estudo do processo estruturado no Brasil sob o governo Jair Bolsonaro e as formas de enfrentamento
}

\author{
Eliara Santana Ferreira*
}

\section{Resumo}

O objetivo deste artigo é discutir como se consolidou um processo de desinfodemia no Brasil a partir de um sistemático processo de desinformação que envolve a disseminação de fake news e o falseamento de notícias científicas a partir da manifestação e do suporte de instâncias públicas federais e de veículos de comunicação aliados às prerrogativas bolsonaristas. A desinfodemia é uma pandemia de desinformação sobre a covid-19, de acordo com estudo divulgado pela Organização das Nações Unidas para a Educação, a Ciência e a Cultura (Unesco). Nesse sentido, visamos a uma sistematização do processo de desinformação no Brasil em tempos da pandemia a partir da suposição de que tal processo reverbera em comportamentos da população em geral, comportamentos esses de desconsideração ou não respeito a recomendações médicas e técnicas e de questionamento em relação aos fatores de contágio e de tratamento da covid, o que pode ser observado preliminarmente a partir das reiteradas matérias jornalísticas que mostram a população nas ruas das principais cidades sem os devidos cuidados de prevenção em relação, por exemplo, ao uso de máscaras. Buscamos, a partir desse levantamento de dados e sua consequente análise, propor um diálogo com base nas ferramentas de letramento midiático e informacional e a 
criação regular de conteúdos que possam auxiliar na promoção de uma cultura midiática mais participativa e na melhor compreensão dos processos de desinformação, auxiliando na prevenção mais efetiva da covid-19 no Brasil.

Palavras-chave: Desinfodemia. Letramento Midiático. Desinformação. Fake news.

\title{
Disinformation, disinfodemic and media information literacy - a study of the process in Brazil under Jair Bolsonaro's government
}

\begin{abstract}
The proposal of this research is to verify how disinfodemic process was consolidated in Brazil fromsystematic dissemination of fake news and misinformation that found support in federal public instances. Disinfodemic is a pandemic of disinformation about covid-19, according to a study released by the United Nations Educational, Scientific, and Cultural Organization (UNESCO). In this sense, we aim at a systematization of the disinformation process in Brazil in times of pandemic from the assumption that such process reverberates in behaviors of the population in general, behaviors that disregard or do not respect medical and technical recommendations and questioning factors of contagion and treatment of covid, which can be observed preliminarily from the repeated journalistic articles that show the population in the streets of major cities without the proper care of prevention in relation, for example, to the use of masks. From this data survey and subsequent analysis, we intend to propose a dialogue based on media and information literacy tools and regularly create content that can help to promote a
\end{abstract}


more participatory media culture and a better understanding of the disinformation processes, which contributes to a more effective prevention of covid-19 in Brazil. The situation of disinformation and consequent disinfodemic is established by the systematic dissemination of false scientific news - such as the dissemination of known incorrect research on the use of certain drugs, for example - by agencies and secretariats of the federal government structure, contrary to scientific precepts established by the World Health Organization.

Keywords: Disinfodemic. Misinformation. Fake News. Media Literacy

Recebido em: 06/07/2021 // Aceito em: 10/09/2021. 


\section{Introdução}

O Brasil vivencia, desde 2018, um processo de desinformação que se tornou incontrolável a partir de 2020, com a pandemia provocada pela covid-19. Tal processo de aprofundamento da crise se deu, sobretudo e essencialmente, em função de uma promoção institucional deliberada de notícias científicas falsas ou falseadas por diversos agentes, nos quais se inserem os agentes do poder público. Entendemos que essa sistemática disseminação provoca uma situação generalizada de desinformação, gerando uma situação de descontrole social entre a população no tocante à compreensão e à observação de regras cientificamente definidas para o controle e o combate da covid-19.

Aliadas a essa conduta de disseminação, as atitudes ostensivas, protagonizadas por agentes públicos (como o Presidente da República) e influencers/comunicadores, de negação em relação a premissas estabelecidas pela Organização Mundial de Saúde (OMS) no tocante ao combate à pandemia (aderir ao isolamento social, usar máscara fora de casa, manter o distanciamento social, evitar aglomerações) também contribuem para o agravamento sistemático da situação sanitária do país. Tal cenário engloba não apenas a disseminação de fake news (por exemplo, espalhando a ideia de que o coronavírus é uma invenção dos chineses), mas também o falseamento do conhecimento científico e a negação de preceitos científicos já secularmente consolidados (como na insistência com o uso de medicamentos já comprovadamente ineficazes no combate à covid-19).

Para enunciar o problema que nos orienta na estruturação deste artigo, fruto de uma pesquisa mais ampla que vimos 
Desinformação, desinfodemia e letramento midiático e informacional - um estudo do processo estruturado no Brasil sob o governo Jair Bolsonaro e as formas de enfrentamento

desenvolvendo, afirmamos que o acesso à informação é um direito reconhecido na Declaração Universal dos Direitos Humanos, reafirmada pela Organização das Nações Unidas e pelo Estado brasileiro, e que a informação plural e de qualidade é elemento essencial também à saúde da população. Como salienta Carlsson (2019), não há boas condições de saúde sem o acesso à informação de qualidade.

Nesse sentido, a nossa tese central é de que, especialmente no momento de uma pandemia, a desinformação que contraria frontalmente - a partir do senso comum e da divulgação de pesquisas comprovadamente fraudulentas ou falseadas preceitos científicos internacionalmente reconhecidos provoca uma situação de caos de informação entre a população. A compreensão em relação aos elementos de verdade e ao movimento de falseamento da verdade, assim como os parâmetros de atribuição do grau de verdade ou de falsidade de qualquer informação constituem um debate que respalda a construção do conhecimento científico na atualidade.

A desinformação é um fenômeno que se consolida nas sociedades contemporâneas, com fortes impactos em vários contextos - social, político, econômico, de saúde -, e isso impacta seriamente o funcionamento da esfera pública, como ressalta Carlsson (2019). Esse fenômeno comunicacional tem grande evidência pelo fenômeno das fake news, mas não deve ser tomado apenas por esse viés: há que se considerar o papel da mídia corporativa, além das mídias digitais, para que se alcance a dimensão desse problema. O falseamento de informações, caracterizando um cenário de desinformação intencional e deliberado, sobretudo em relação às informações científicas, neste momento de pandemia (como as mudanças de cálculo para 
balanços em relação à covid-19, ou a propaganda para utilização de medicamentos não recomendados pela OMS, entre outros diversos exemplos), tem sido determinante para o agravamento da situação de desinformação, que se generaliza e avança rumo a uma situação de desinfodemia.

Nesse sentido, o processo de desinformação sistemático como se observa no Brasil no cenário do alastramento da covid-19 está em consonância com o fenômeno descrito pela Organização das Nações Unidas para a Ciência, a Educação e a Cultura (Unesco) como desinfodemia, uma pandemia pela desinformação básica sobre a doença, conceito que iremos detalhar a seguir.

Assim, o objetivo deste artigo é discutir o contexto da desinfodemia no Brasil, considerando-o como parte de um processo avançado de desinformação que se estrutura a partir de vários agenciamentos e agentes, e o papel do letramento midiático e informacional como ferramenta prática e arcabouço teórico capaz de consolidar a formação crítica de cidadãos e cidadãs, tornando-se um instrumental de combate a esse processo.

\section{Desinformação e desinfodemia no Brasil}

\subsection{A estrutura de desinformação}

Na busca por compreender a complexidade desse fenômeno no Brasil contemporâneo, tomamos as construções propostas por Wardle (2019) e Carlsson (2019), que abordam a desinformação em sua complexidade, extrapolando a discussão sobre a estrutura e/ou disseminação de fake news, portanto, para além também 
Desinformação, desinfodemia e letramento midiático e informacional - um estudo do processo estruturado no Brasil sob o governo Jair Bolsonaro e as formas de enfrentamento

de uma discussão pautada pela preocupação em se estabelecer uma diferenciação entre verdadeiro ou falso, uma vez que há, no desenrolar desses fenômenos, processos de falseamento de um dado real, como veremos adiante, no material coletado.

Assim, começamos por trazer o que Wardle (2019) ${ }^{1}$ salienta como tipos do que compõem uma desordem informacional:

- Disinformation: uma informação que é falsa e deliberadamente criada para causar prejuízos. Ela é motivada por três fatores distintos: obtenção de lucro, para que grupos tenham influência política (interna ou externa) ou para causar problemas específicos a grupos, a pessoas ou a um país;

- Misinformation: informação que é falsa, mas não criada com a intenção de causar danos;

- Mal-information: informação baseada na realidade, usada para causar prejuízos a pessoas ou grupos.

A partir dessa categorização inicial, propomos então uma conceituação para pensarmos o fenômeno da desinformação no Brasil, o qual tomaremos como um processo estruturado por um conjunto de informações falsas ou falseadas, muitas vezes baseadas num dado real, num dado da realidade, intencionalmente e deliberadamente criadas ou ressignificadas para prejudicar determinados grupos e beneficiar outros e que são criadas e disseminadas sistematicamente por agentes específicos, num esquema de comunicação profissional. Portanto, não são práticas aleatórias nem oriundas de práticas individuais.

Nessa abordagem, Wardle (2019) destaca sete diferentes tipos da desinformação, que são:

\footnotetext{
1 Em setembro de 2017, Claire Wardle, juntamente com Hossein Derakhshan, foi autora do documento "Report of the Council of Europe - Information Disorder. Toward an interdisciplinary framework for research and policymaking” (September 2017), onde já se apresenta essa discussão.
} 
- Conteúdo falso: novo conteúdo que é 100\% falso, projetado para enganar e causar danos;

- Conteúdo manipulado: quando informações ou imagens genuínas são manipuladas para enganar;

- Conteúdo impostor: quando fontes genuínas são representadas em textos, artigos, matérias que não escreveram, ou em declarações que não deram, ou ainda quando $\log o s$ de instituições são usadas para reproduzir conteúdos;

- Conteúdo enganoso: uso enganoso de informações para enquadrar um problema ou indivíduo. A fragmentação da informação está longe de ser nova e se manifesta de inúmeras maneiras. A reformulação das histórias nas manchetes, o uso de fragmentos de aspas para sustentar um ponto mais amplo, citando as estatísticas de uma maneira que se alinha com uma posição ou decidindo não cobrir alguma coisa, porque isso prejudica um argumento, são todas técnicas reconhecidas;

- Conexão falsa: quando manchetes, imagens ou legendas não correspondem ao conteúdo. Como parte do debate sobre desordem da informação, é necessário que a indústria de notícias reconheça seu próprio papel na criação de conteúdo que não atende aos altos padrões exigidos por uma indústria agora atacada por vários lados, salienta a autora;

- Contexto falso: conteúdos genuínos são frequentemente vistos sendo reciclados fora de seu contexto original.

Esses aspectos destacados por Wardle (2019) não se restringem à abordagem sobre fake news ou exclusivamente à comunicação via internet, nas redes sociais; elas também encontram suporte e respaldo nas práticas da mídia corporativa, 
Desinformação, desinfodemia e letramento midiático e informacional - um estudo do processo estruturado no Brasil sob o governo Jair Bolsonaro e as formas de enfrentamento

em rádios, TVs, jornais e revistas. Vamos trazer apenas um exemplo específico para mostrar essa colocação, ainda que a abordagem relativa à estrutura da mídia corporativa não seja o foco deste artigo. Assim, uma ilustração de conteúdo enganoso praticado pela mídia corporativa pode ser observado em uma matéria do Jornal Nacional de 9 de outubro de 2019, cujo tema era inflação. A abertura da matéria ressalta: "O índice que mede a inflação oficial do Brasil registrou deflação de 0,04\% em setembro. Foi a maior retração média de preços para o mês desde 1998. Alimentos e bebidas foram os que mais contribuíram para isso. Nos últimos 12 meses, o IPCA registra inflação de 2,9\%, bem abaixo da meta do governo pra esse ano [...]". A reportagem não explica o que é de fato deflação, e o tom da notícia induz a uma percepção positiva - a de que os preços estavam caindo porque o governo estava controlando a inflação. No entanto, deflação significa que a renda, o emprego e o consumo estão ruins, estão prejudicados, o que revela, na verdade, algo negativo, ou seja, que a economia está fraca e desaquecida.

\subsection{Cenário brasileiro}

\subsubsection{Panorama da desinformação no Brasil}

O sistema de desinformação no Brasil precisa ser considerado a partir de algumas prerrogativas para situarmos o problema para além de questões trazidas contemporaneamente pelas redes sociais, pela mídia digital. É um equívoco que se problematize a desinformação apenas por um viés, a partir do advento das mídias digitais. No Brasil, o fenômeno pode ser analisado a partir de alguns elementos centrais: 
a) Pouca pluralidade no acesso da população à informação há uma predominância de meios tradicionais convencionais e acesso precário à internet;

b) Grande disseminação de fake news e de notícias falseadas operacionalizada por diversas instâncias (públicas e privadas), como o provam sites disseminadores de conteúdo falso em relação à covid-19;

c) Mídia altamente concentrada no controle de poucos grupos - apenas sete grupos;

d) Grupos religiosos com perfil muito conservador com controle cada vez maior da mídia tradicional;

e) Uso massivo de WhatsApp pela população.

Trata-se, sem dúvida, de um fenômeno complexo em que várias ocorrências - antigas e recentes - se coadunam para produzi-lo e ampliar sua potencialidade e que é agravado por um cenário de pandemia em que agentes públicos divergem frontalmente entre si e não são capazes de orientar adequadamente a população. Esse cenário esgarça de tal forma o tecido social que há uma rápida evolução para uma situação de desinfodemia, que tem no cerne os fenômenos das fake news e do falseamento de notícias sobretudo científicas, implicando num retrocesso em termos de controle da pandemia de covid-19 no país.

Para ilustrar, trazemos o seguinte esquema: 
Desinformação, desinfodemia e letramento midiático e informacional - um estudo do processo estruturado no Brasil sob o governo Jair Bolsonaro e as formas de enfrentamento

\section{Figura 1}

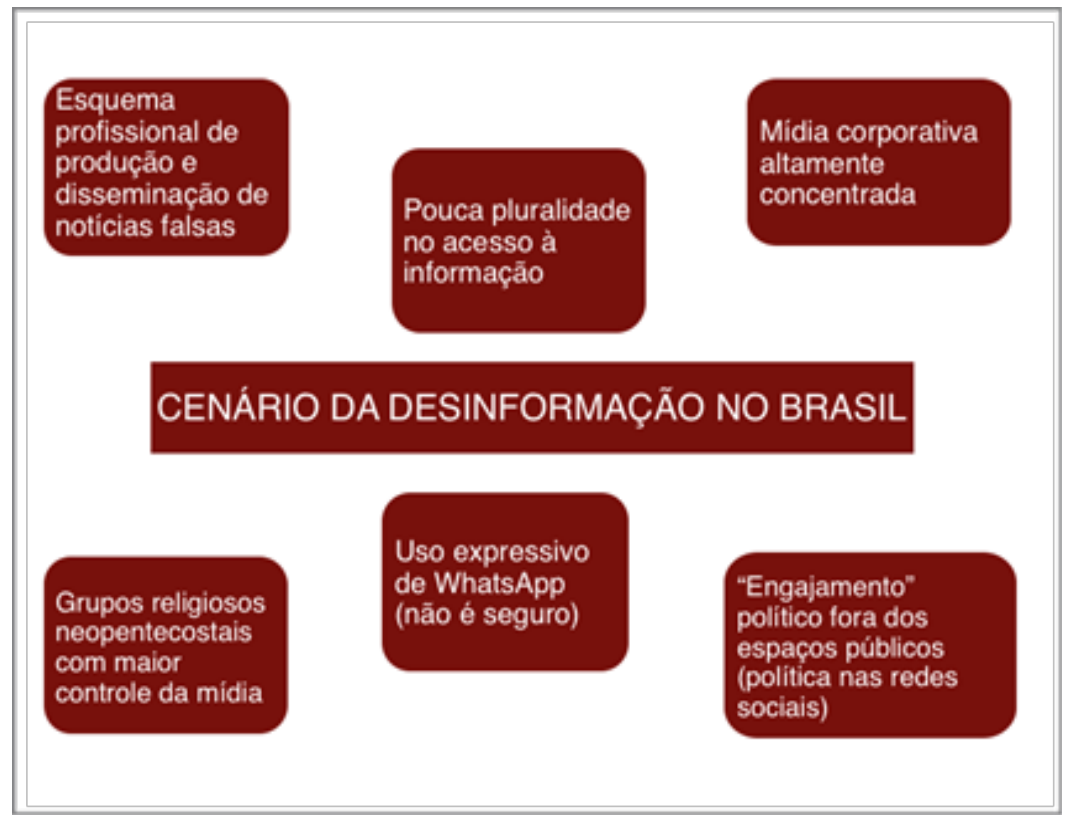

Fonte: Elaborada pela autora.

Como podemos observar na Figura 1, o cenário da desinformação no Brasil é bastante complexo e envolve vários elementos que não se esgotam na observação do processo de disseminação de fake news. A estrutura da mídia corporativa também colabora muito para esse cenário, uma vez que apenas sete grupos controlam a produção de informação e de entretenimento no país; a regulamentação da radiodifusão ainda não está efetivada; apenas quatro grandes grupos de TV aberta respondem por $70 \%$ da audiência no país, e $80 \%$ dos meios de comunicação estão concentrados na Região Sudeste do país. ${ }^{2}$

Neste artigo, não vamos nos aprofundar nesses dados e abordagens, pois vamos nos deter mais especificamente na

2 Dados da pesquisa Media Ownership Monitor/Intervozes, de 2018. 
pesquisa que efetivamos em relação à estruturação de cenário de desinfodemia a partir da pandemia de covid-19 no país.

\subsubsection{Um ecossistema de fake news}

Uma das pontas desse sistema de desinformação no Brasil é o ecossistema de fake news. A construção desse ecossistema foi adaptado à realidade brasileira a partir de uma abordagem da pesquisadora Yoana Literat, do Media and Social Change Laboratory (MASClab), do Teachers College, Columbia University. ${ }^{3}$ E por que pensar numa representação como essa? Porque o esforço de compreensão do fenômeno das fake news no Brasil implica considerar a perspectiva de um processo bem estruturado, com vários momentos e atores, de construção de significado que acaba por ressignificar a realidade, que se consolida e cria novas dimensões de sentido, com graves consequências pelo alcance sistêmico e pelas influências marcantes no cenário macropolítico e na reestruturação do papel de instâncias como a imprensa tradicional, por exemplo.

Tomamos o conceito de fake news a partir da elaboração de Allcott e Gentzkow (2017), segundo os quais as fake news são "informações difundidas por meios de comunicação que se disfarçam de veículos jornalísticos e que difundem informação comprovadamente incorreta para enganar seu público [...]".

No Brasil, um modelo possível de ecossistema pode ser pensado a partir da seguinte estrutura:

3 Fiz parte do Masclab em 2019, ocasião em que, a partir de um esboço já existente e desenvolvido pela professora Yoana Literat, projetei a arquitetura desse sistema adaptado à realidade brasileira. 
Desinformação, desinfodemia e letramento midiático e informacional - um estudo do processo estruturado no Brasil sob o governo Jair Bolsonaro e as formas de enfrentamento

Figura 2

\section{Ecossistema 2 FakeNews}

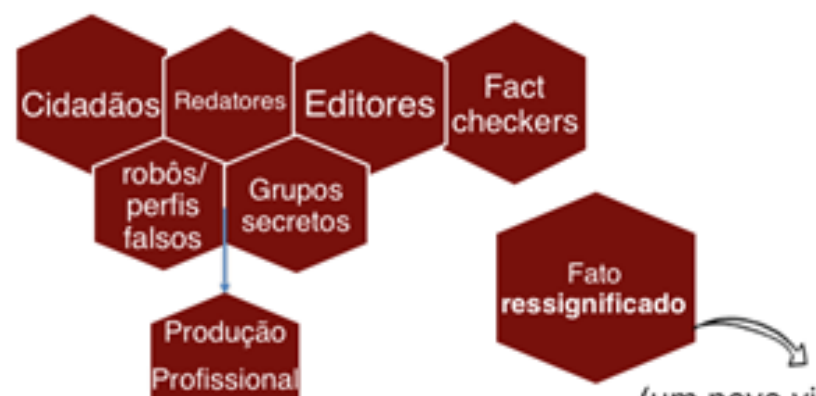

(um novo viés

que é intencional, com grande alcance político)

Fonte: Elaborado pela autora.

Consideramos esse ecossistema, a partir de Stuart Hall (1973), como um processo de codificação/decodificação, em que vários fatores (de ambos os lados) afetam o modo como as mensagens são produzidas, a roupagem que recebem e a sua circulação. Fatores como: origem das mensagens, autoria, imagens usadas, contexto político-social, intencionalidade. É uma estrutura sustentada pela articulação destes quatro momentos distintos: produção (a codificação da mensagem tem lugar), circulação (como os indivíduos percebem as mensagens), uso/consumo (interpretação da mensagem) e reprodução (se os indivíduos desenvolvem ações depois de receberem as mensagens). No caso brasileiro, percebemos a configuração de uma estrutura que envolve agentes profissionais - sites, blogs, portais - que se aliam a influencers e apresentadores de programas televisivos. 
Essa estrutura profissional não é observada somente em relação ao processo de disseminação de fake news (não se trata somente de um impulsionamento), mas também no processo de produção - a desinformação veiculada tem uma roupagem de notícia. Redatores e editores marcados como partes da colmeia na Figura 2 compõem o esquema de produção, enquanto que robôs, bots e grupos secretos integram o esquema de disseminação. Nos dois extremos da colmeia, estão os cidadãos e as agências de checagem. Esse ecossistema teve e tem, até este ano de 2021, um papel essencial no processo de desinfodemia no Brasil.

\subsection{Desinfodemia}

$\mathrm{O}$ conceito de desinfodemia refere-se à pandemia de desinformação ligada à pandemia de covid-19 e foi cunhado a partir da pesquisa "Disinfodemic - Deciphering Covid-19 Desinformation", desenvolvida pela Unesco em 2020. De acordo com a pesquisa, a desinformação que se vincula à covid-19 ameaça não apenas os indivíduos, mas as sociedades como um todo, pois ela leva os cidadãos a causarem prejuízos a si próprios ao ignorarem as recomendações científicas. De acordo com o documento, "as motivações para a desinformação são diversas. Elas podem ser para ganhar dinheiro, obter vantagens políticas, minar a confiança, transferir a culpa, polarizar as pessoas e prejudicar as respostas à pandemia". ${ }^{4}$

A pesquisa ressalta que o acesso à informação de qualidade é um aspecto essencial para combater a desinformação e a desinfodemia e destaca respostas necessárias a vários aspectos

4 Nossa tradução para: "The motivations for the disinformation are diverse. They may be to make money, score political advantage, undermine confidence shift blame, polarise people, and to undermine responses to the pandemic [...]" (Disinfodemic - Deciphering covid-19 Desinformation”, Unesco, 2020, p. 5). 
Desinformação, desinfodemia e letramento midiático e informacional - um estudo do processo estruturado no Brasil sob o governo Jair Bolsonaro e as formas de enfrentamento

sociais, culturais e econômicos. Em relação à educação, o documento ressalta que "as respostas propostas e discutidas visam promover o letramento midiático e informacional dos cidadãos, o qual inclui pensamento crítico e habilidades de verificação digital [...]" (Unesco, 2020, p. 13). Cabe aqui, brevemente, ponderar a tênue diferença entre os conceitos de infodemia e desinfodemia, para que não exista o entendimento de que se trata do mesmo fenômeno. A infodemia compreende uma situação de excesso de informação, não necessariamente informação incorreta, mas um excesso de informações muitas vezes de baixa qualidade e que podem também ser incorretas. A desinfodemia refere-se, como já dito, especificamente à pandemia de desinformação relativa à pandemia de covid-19 e tem aspectos bastante específicos.

2.3.1 Nove temas principais da pandemia de desinformação

O documento divulgado pela Unesco em abril de 2020 destaca que as fake news recorrentes nesse processo referem-se principalmente a tópicos como: origem e disseminação do novo coronavírus, sintomas, diagnóstico e tratamento, estatísticas falsas e reflexos econômicos. No Brasil, pode-se observar que os vetores citados como responsáveis pela disseminação de desinformação (peças publicitárias oficiais, manifestações via redes sociais de agentes públicos, entre outros) utilizam-se desses elementos. De acordo com o documento:

A desinformação em relação à COVID-19 cria confusão sobre a ciência médica com impacto imediato em cada pessoa no planeta e em sociedades inteiras. É mais tóxico e mais mortal do que a desinformação sobre 
outros assuntos. É por isso que este documento cunha o termo desinfodemia [...] (Unesco, 2020, p. 2). ${ }^{5}$

Os nove temas principais são:

1) Origem e disseminação do novo coronavírus: há várias teorias culpando diversos atores pelo surgimento da doença, e, segundo a pesquisa, "usando-se um rótulo como 'vírus chinês', em vez de terminologia neutra, infla-se a localização em um adjetivo, em um eco histórico que deu um significado tendencioso [...]";

2) Estatísticas falsas e enganosas: frequentemente ligadas à incidência da doença e a taxas de mortalidade;

3) Impactos econômicos: disseminação de falsas notícias sobre os impactos econômicos e de saúde da pandemia, "sugerindo que o isolamento social não é economicamente justificável e mesmo afirmações de que a Covid-19 está criando empregos [...]";

4) Desacreditação de jornalistas e de veículos de notícias confiáveis: há campanhas contra órgãos tradicionais de imprensa;

5) Sintomas, diagnóstico e tratamento: conteúdo inclui desinformação perigosa sobre a prevenção, o tratamento e a cura da doença;

6) Impactos na sociedade e no meio ambiente: inclui falsa informação sobre lockdowns, por exemplo;

7) Politização: segundo a pesquisa, esse item engloba informações apresentadas para negar o significado de fatos que são inconvenientes para certos atores no poder e desinformações projetadas para enganar e obter vantagem

5 Nossa tradução para: “COVID-19 disinformation creates confusion about medical science with immediate impact on every person on the planet, and upon whole societies. It is more toxic and more deadly than disinformation about other subjects. That is why this policy brief coins the term disinfodemic [...]". 
Desinformação, desinfodemia e letramento midiático e informacional - um estudo do processo estruturado no Brasil sob o governo Jair Bolsonaro e as formas de enfrentamento

política, o que inclui equiparar a covid-19 à gripe e fazer afirmações sem fundamento sobre a duração provável da pandemia;

8) Conteúdo impulsionado por ganho financeiro fraudulento: inclui golpes destinados a roubar os dados privados das pessoas;

9) Desinformação focada em celebridades: falsas histórias sobre personalidades que contraíram a doença e se curaram. Além desses temas, o documento também indica quatro formatos principais que prevalecem na estrutura da desinfodemia. São eles:

1) Narrativas emotivas (construções textuais e memes): textos narrativos que frequentemente misturam linguagem emocional forte, mentiras e/ou informações incompletas e opiniões pessoais juntamente com elementos de verdade. Esses formatos são particularmente difíceis de serem descobertos em mensagens fechadas;

2) Sites fabricados e identidades de autoridades: fontes falsas, conjuntos de dados poluídos e sites falsos ligados ao governo ou de empresas e sites que publicam informações aparentemente plausíveis no gênero de notícias, por exemplo, relatando casos fictícios de covid-19;

3) Imagens e vídeos fraudulentamente alterados, fabricados ou descontextualizados: são usados para criar confusão e desconfiança generalizada e/ou evocar emoções fortes por meio de memes virais ou histórias falsas;

4) Disseminadores de desinformação e campanhas orquestradas: ações destinadas a semear a discórdia em comunidades on-line, avançar o nacionalismo e as agendas geopolíticas, fazer coleta ilícita de dados pessoais de saúde 
ou obter ganho monetário com spam e anúncios de curas falsas. Tais formatos também podem incluir a ampliação e o antagonismo de artificialismo por bots e trolls como parte de campanhas organizadas de desinformação.

Partindo da construção conceitual já delineada e para compreender as bases do desenvolvimento desse complexo sistema no Brasil, especialmente sob o governo Jair Bolsonaro, tomamos como objetos de análise, considerando-se o ecossistema de fake news, o alcance e a potencialidade de danos desse processo, postagens e campanhas da Secretaria de Comunicação do Governo Federal (Secom), no período de abril a dezembro de 2020, e matérias publicadas em dois sites favoráveis ao governo Bolsonaro, que são "Estudos Nacionais" e "Jornal da Cidade Online". Para consolidar essas investigações, nos baseamos também em resultados da pesquisa "As palavras importam (2020)", desenvolvida pela Fundação Getúlio Vargas e a Universidade de Cambridge.

Esse estudo mostrou que, nas cidades nas quais Jair Bolsonaro teve mais votos na eleição de 2018, mesmo num cenário em que as pessoas têm mais acesso à informação (via TVs, rádios, internet e jornais), a queda no isolamento social foi maior após as falas e o comportamento do presidente da República. Os pesquisadores utilizaram dados de geolocalização de 60 milhões de aparelhos celulares (dados anônimos) e, em seguida, cruzaram esses dados com as informações sobre a votação na eleição de 2018 (dados do TSE). Eles consideraram dois momentos específicos, os dias 15 e 24 de março de 2020, quando o presidente Bolsonaro minimizou os impactos da covid-19 no Brasil. A pesquisa mostrou que os níveis de adesão às medidas de isolamento social e de quarentena caíram até três pontos percentuais nesses dois momentos, ou seja, a partir das declarações do presidente. 
Desinformação, desinfodemia e letramento midiático e informacional - um estudo do processo estruturado no Brasil sob o governo Jair Bolsonaro e as formas de enfrentamento

Também consideramos, em nossa pesquisa, as lives, os tuítes e as declarações públicas do presidente da República, Jair Bolsonaro, em defesa dos medicamentos cloroquina e hidroxicloroquina, contra o distanciamento social e o uso de máscaras e com críticas a vacinas, em diferentes momentos, ao longo do ano de 2020 e até junho de 2021. Essas manifestações estão exemplificadas no Quadro 1.

\section{Quadro 1 - Exemplos de declarações do Presidente da República}

\begin{tabular}{|l|l|}
\hline \multicolumn{1}{|c|}{ Data } & \multicolumn{1}{c|}{ Exemplo } \\
\hline $19 / 12 / 2020$ & $\begin{array}{l}\text { "Eu tive infectado no ano passado, tomei } \\
\text { aquele remédio que eu dei pra ema, aquele } \\
\text { remédio pra combater a malária. No dia } \\
\text { seguinte tava bom" }\end{array}$ \\
\hline $11 / 04 / 2020$ & $\begin{array}{l}\text { "A hidroxicloroquina é a alternativa no } \\
\text { momento contra a covid-19" }\end{array}$ \\
\hline $24 / 06 / 2021$ & $\begin{array}{l}\text { "E eu recomendo que você procure um } \\
\text { médico e inicie imediatamente o tratamento, } \\
\text { tendo sido vacinado ou não." }\end{array}$ \\
\hline $14 / 05 / 2020$ & $\begin{array}{l}\text { "Cada dia você vê mais aqui que quem } \\
\text { praticou o lockdown não deu certo." }\end{array}$ \\
\hline
\end{tabular}

Fonte: Elaborado pela autora.

Em consonância com a conceituação apresentada, os tópicos descritos e a discussão proposta pelo documento da Unesco, observa-se no Brasil a promoção crescente de descrédito em relação a prerrogativas científicas da OMS e de outras instituições de pesquisa brasileiras e um processo oficial de disseminação de desinformação promovido por agentes públicos no momento de agravamento da pandemia de covid-19 no país. Além das declarações presidenciais, podemos mostrar ainda, como agentes desse processo, ações institucionais de divulgação 
de tratamentos e remédios ineficazes contra a covid-19, como a campanha exemplificada a seguir, que foi promovida pela Secretaria de Comunicação (Secom) do Governo, em maio de 2020, e difundida oficialmente:

\section{Figura 3 - Propaganda hidroxicloroquina divulgada pela Secom em rede social em 21-05}

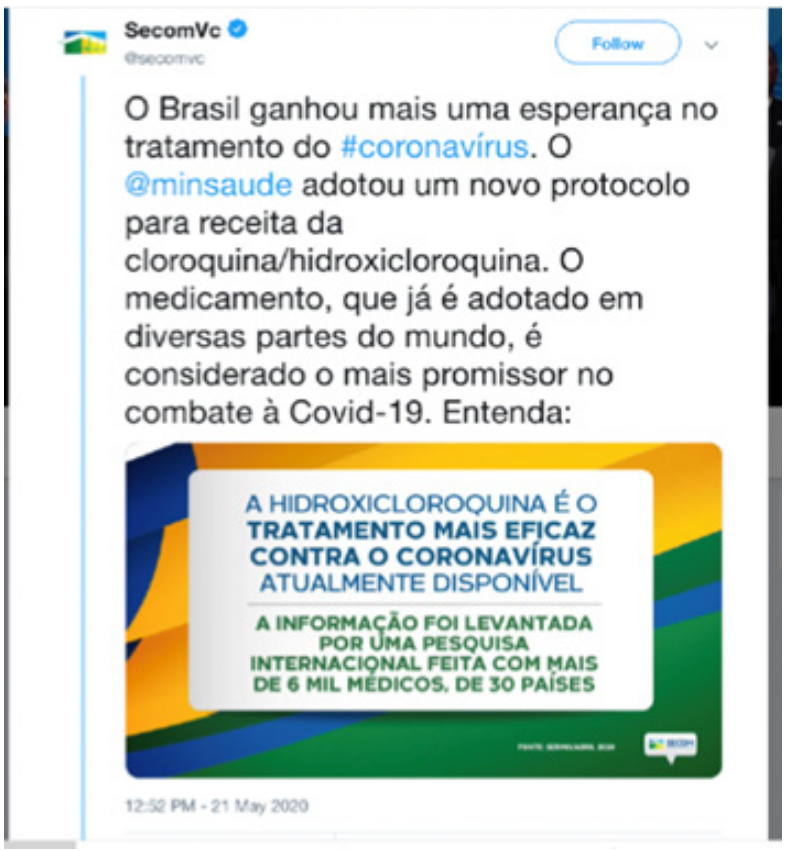

Fonte: Perfil SecomVe no Twitter.

Há nessa peça publicitária um falseamento do conhecimento científico brasileiro e também internacional, uma vez que o elemento principal usado como substrato da desinformação é a hidroxicloroquina, amplamente pesquisada e já desacreditada na comunidade científica e, recentemente, não recomendada oficialmente pela OMS. Tal defesa, explicitada na peça de comunicação, encontrou resistência no âmbito das ações definidas 
Desinformação, desinfodemia e letramento midiático e informacional - um estudo do processo estruturado no Brasil sob o governo Jair Bolsonaro e as formas de enfrentamento

pelos governos estaduais, que promovem também campanhas de orientação para a população dos seus respectivos estados em conformidade com a orientação máxima da Organização Mundial de Saúde, que não recomenda tal medicamento e afirma sua ineficácia no combate à covid-19, além dos efeitos colaterais graves.

Com o alastramento pelo país da pandemia de covid-19, o Brasil passou a vivenciar uma situação de negacionismo em relação a preceitos científicos e o falseamento ostensivo de notícias científicas no que diz respeito às formas de combater a covid-19, ações observadas em agentes públicos e em parte da população. E tal contexto se soma ao já complexo ambiente de disseminação de fake news, situação que ocasiona dificuldades crescentes para o controle da pandemia no país.

Dado esse cenário complexo de desinfodemia no Brasil, uma questão posterior que se insere é em relação às ações e aos instrumentos que podem ser eficazes para a estruturação de um combate sistemático e efetivo ao processo em curso - que tem implicações sérias para o combate à covid-19, como já alertado pela OMS, pelo Alto Comissariado de Direitos Humanos da ONU e pelo Unicef.

A primeira hipótese nesse sentido é a de construção de processos de educação em letramento midiático e informacional, constituindo-se num programa efetivo para auxiliar os públicos a desenvolverem uma compreensão crítica da natureza da mídia, suas técnicas de convencimento e argumentação e o impacto do discurso de informação na sociedade, fortalecendo a participação democrática e o engajamento cívico, funcionando como antídoto às fake news e à proliferação do discurso de ódio. 
É necessário que se elaborem e se estruturem instrumentos e metodologia para a identificação da estrutura de desinfodemia no país, buscando-se uma compreensão adequada do fenômeno das fake news e do falseamento de informações com caráter científico no Brasil durante a pandemia de covid-19, bem como dos agentes propagadores, como forma de contribuir para um combate eficaz da doença e suas implicações no combate à covid-19. O Brasil tem experimentado os efeitos bastante negativos da conjunção desses dois elementos, que causa um esgarçamento do tecido social e coloca em xeque o funcionamento das instituições, o que tem se intensificado durante a pandemia em relação ao falseamento de questões científicas.

\section{Letramento midiático e democracia}

O letramento midiático é um conjunto de habilidades, ferramentas, conhecimentos que constrói uma compreensão do papel das mídias na sociedade, bem como ferramentas de questionamento para os cidadãos se posicionarem. Segundo Hobbs (2009):

O letramento midiático foi conceituado em relação a quatro posições teóricas primárias: como um meio para combater os efeitos negativos dos meios de comunicação de massa; como uma forma de combater o poder hegemônico dos meios de comunicação de massa; como uma forma de reconhecer a estrutura e a natureza construída das mensagens da mídia; e como uma forma de reconhecer o papel do jogo, identidade, voz e subjetividade nas práticas de consumir e criar meios de comunicação. Cada uma destas quatro tradições tem seus adeptos e detratores, o que contribuiu para alguns dos "grandes debates" no campo [...] (HOBBS, 2009, p. 25). 
Desinformação, desinfodemia e letramento midiático e informacional - um estudo do processo estruturado no Brasil sob o governo Jair Bolsonaro e as formas de enfrentamento

Segundo a autora, o conceito de letramento midiático circula nos Estados Unidos e na Europa desde o início do século 20 e se consolida como um conjunto de conhecimentos e habilidades que são necessários para a plena participação em uma sociedade que está às voltas com o excesso de mídia contemporânea. Ainda de acordo com Hobbs (2009), a aquisição das competências de letramento midiático não pode ser tomada apenas como um conjunto de habilidades técnicas e operacionais, é preciso, ela ressalta, perceber essas competências como parte de um processo de mudança cultural.

Portanto, o letramento midiático constitui-se como um arcabouço para a formação de cidadãos críticos, nas mais diversas instâncias, que sejam capazes de identificar e se posicionar diante de um complexo sistema de desinformação, em que o processo de desinfodemia observado no Brasil recentemente se insere. Os processos eleitorais e a própria democracia ficam reféns da desinformação. Como salienta a Unesco, "uma sociedade alfabetizada em mídia e informação promove o desenvolvimento de mídias livres, independentes e pluralistas, e de sistemas abertos de informação [...]".

Ao problematizar o impacto da desinformação para a democracia, Carlsson (2019) ressalta que a diferença no acesso aos meios, à internet e à informação e na habilidade do uso das mídias reforça um modelo já existente de desigualdade socioeconômica. De acordo com a pesquisadora, o letramento midiático e informacional deve ser considerado como um direito da cidadania, sendo crucial para o funcionamento da democracia, pois o aumento da desinformação e da má informação tem um impacto muito sério na esfera pública. E a diferença no acesso à mídia e à informação de qualidade, aponta ela, contribui para o aumento da desigualdade. 
Para Jenkins (2006), a consolidação de práticas de letramento midiático contribui fortemente para a criação de uma cultura participativa que contribui para o engajamento civil e a formação de uma cultura cívica. E isso importa porque, de acordo com o autor, os produtos e conteúdos do sistema midiático terão apoio (credibilidade) e serão disseminados apenas se o sistema cultural de determinada sociedade der suporte a isso.

Para justificar a relevância do ensino de letramento midiático, Jenkins (2006) destaca três problemas principais, e aqui nós optamos por abordar os dois mais relevantes do ponto de vista da realidade brasileira. O primeiro, ele diz, refere-se à lacuna, ou vácuo de participação, pois há um acesso desigual da população à informação e aos canais de participação cívica, sobretudo em relação à internet. $\mathrm{O}$ acesso não é igual para todos. O segundo problema que o autor destaca diz respeito à transparência na e da produção dos conteúdos midiáticos. Segundo ele, mesmo que os jovens e adultos em geral usem os recursos midiáticos, sobretudo digitais, eles são limitados em sua habilidade para examinar o sistema de mídia como um todo.

Segundo a Unesco, a alfabetização midiática e informacional tem um enorme poder agregador de criação de diversas interfaces entre muitos e diversos grupos sociais e a possibilidade concreta do estabelecimento de conexões em várias partes do mundo, por meio do contato com ONGs e outras formas de atuação, bem como a possibilidade de criação de diversas experiências contemplando esse trabalho. A Unesco diferencia os elementos da alfabetização midiática e da alfabetização informacional, como se segue: ${ }^{6}$

\footnotetext{
$\overline{6}$ De acordo com a Unesco, "por um lado, a alfabetização informacional enfatiza a importância do acesso à informação e a avaliação do uso ético dessa informação. Por outro, a alfabetização midiática enfatiza a capacidade de compreender as funções da mídia, de avaliar como essas funções são desempenhadas e de engajar-se racionalmente junto às mídias com vistas à autoexpressão [...]".
} 
Desinformação, desinfodemia e letramento midiático e informacional - um estudo do processo estruturado no Brasil sob o governo Jair Bolsonaro e as formas de enfrentamento

Figura 4 - Duas formas de alfabetização

\begin{tabular}{|c|c|}
\hline & ação \\
\hline Alfabetização informacional & Alfabetização midiática \\
\hline $\begin{array}{c}\text { Definição e articulação de necessidades } \\
\text { informacionais }\end{array}$ & $\begin{array}{l}\text { Compreensão do papel e das funções das } \\
\text { midias em sociedades democráticas }\end{array}$ \\
\hline Acesso à informação & $\begin{array}{l}\text { Compreensão das condições sob as quais as } \\
\text { midias podem cumprir suas funções }\end{array}$ \\
\hline Localização e acesso à informação & $\begin{array}{l}\text { Avaliação crítica do conteúdo midiático à luz } \\
\text { das funções da mídia }\end{array}$ \\
\hline Organização da informação & $\begin{array}{l}\text { Compromisso junto às midias para a } \\
\text { autoexpressão e a participação democrática }\end{array}$ \\
\hline Uso ético da informação & $\begin{array}{c}\text { Revisãa das habilidades (incluindo as TICs) } \\
\text { necessánias para a produção de conteúdos pelos } \\
\text { usuánios }\end{array}$ \\
\hline
\end{tabular}

Fonte: Elaborado pela autora a partir de dados e conceitos da Unesco.

Na pesquisa e neste artigo, pela dimensão político-social transformadora, adotamos a concepção de letramento midiático e informacional. 


\subsection{Os core concepts do letramento midiático}

As diversas tecnologias envolvidas, bem como o instrumental educacional específico envolvido, traz inúmeras possibilidades no campo do letramento midiático, seja na formação específica de professores, seja no desenvolvimento de ferramentas de ensino para crianças e jovens e adultos. Os core concepts do letramento midiático são essenciais para 0 desenvolvimento de sua compreensão e prática e também para a estruturação de uma análise crítica dos meios. De acordo com o Center for Media Literacy (CML), há cinco core concepts, que são:

1) Autoria - todas as mensagens da mídia são construídas;

2) Formato - as mensagens da mídia são construídas usandose uma linguagem criativa com suas próprias regras;

3) Audiência - diferentes pessoas experimentam a mesma mensagem da mídia de modo diferente;

4) Conteúdo - a mídia embute valores e pontos de vista em seu conteúdo;

5) Propósitos - a maioria das mensagens da mídia são organizadas para obter benefícios ou poder.

A partir deles temos, então, as principais habilidades a serem desenvolvidas e a serem trabalhadas para empreender uma educação para a mídia:

Analisar - É necessário desenvolver competências analíticas entre os leitores, ouvintes, espectadores e usuários das redes sociais, que devem ser formados no sentido de serem competentes para interpretar os conteúdos;

Avaliar - A avaliação crítica é essencial para o letramento. Nesse processo, é fundamental dotar o público de conhecimento 
Desinformação, desinfodemia e letramento midiático e informacional - um estudo do processo estruturado no Brasil sob o governo Jair Bolsonaro e as formas de enfrentamento

sobre os contextos sociais, culturais, econômicos, políticos e históricos mais amplos nos quais o conteúdo midiático é produzido;

Criar - Levando-se em consideração sobretudo o público adolescente - a juventude -, é essencial que ele se aproprie também da produção de conteúdo, transformado-se em remetente e produtor de mensagens informacionais de qualidade. $\mathrm{O}$ letramento midiático não se destina a construir uma "proteção" para as crianças, livrando-as de conteúdos danosos.

O letramento midiático também não se resume a um instrumental para compreender a mídia - trata-se de um processo para desenvolver habilidades nos cidadãos para que eles construam um pensamento crítico. Segundo Masterman (1985):

$\mathrm{O}$ conceito unificador central da Educação para a Mídia é o da representação. A mídia media. Eles não refletem, mas reapresentam o mundo. Os meios, é isto, são sistemas simbólicos de signos que devem ser descodificados. Sem este princípio, nenhuma educação midiática é possível. A partir dele, todo o resto flui [...] (MASTERMAN, 1985, p. 30).

\subsection{Por que o letramento midiático é importante?}

O Centro de Letramento Midiático (CML) aborda alguns elementos para demonstrar por que o letramento midiático é um instrumento tão relevante no século $21:^{7}$

A influência da mídia nos processos democráticos centrais: Numa cultura global midiática, as pessoas precisam de duas habilidades para serem cidadãos engajados de uma democracia:

7 Resumo elaborado a partir de Len Masterman, em Teaching the Media (1985). 
pensamento crítico e autoexpressão. A alfabetização midiática instiga essas duas habilidades essenciais, permitindo que os futuros cidadãos possam classificar por meio de embalagens políticas, entender e contribuir para o discurso público e, em última instância, tomar decisões informadas nos processos eleitorais;

A alta taxa de consumo de mídia e a saturação da sociedade pela mídia: Quando se consideram videogames, televisão, música pop, rádio, jornais, revistas, outdoors, internet etc., estamos expostos a mensagens mais mediatizadas em um dia do que os nossos bisavós foram expostos em um ano. A alfabetização midiática ensina as habilidades que precisamos para navegar com segurança por este mar de imagens e mensagens - para toda a nossa vida;

A influência da mídia na formação de percepções, crenças e atitudes: É inquestionável que as experiências da mídia exercem um impacto significativo na forma como entendemos, interpretamos e agimos em nosso mundo. Ao nos ajudar a compreender essas influências, a educação midiática pode nos ajudar a sair da dependência em relação a elas;

A crescente importância da comunicação visual e da informação: A vida das pessoas é cada vez mais influenciada por imagens visuais - de logotipos corporativos a outdoors de tamanho de edifício a sites da Internet. Aprender a "ler" as múltiplas camadas da comunicação baseada na imagem é um complemento necessário à alfabetização tradicional da impressão. O mundo é multimídia;

A importância da informação na sociedade e a necessidade de aprendizagem ao longo da vida: $\mathrm{O}$ crescimento das indústrias globais dos meios também desafia vozes independentes e visões 
Desinformação, desinfodemia e letramento midiático e informacional - um estudo do processo estruturado no Brasil sob o governo Jair Bolsonaro e as formas de enfrentamento

diversas. A educação para a mídia pode ajudar tanto professores quanto alunos a entender de onde vem a informação e como encontrar pontos de vista alternativos.

\subsection{O letramento midiático na sala de aula}

Há inúmeras possibilidades de se construir, em sala de aula, um trabalho efetivo de desenvolvimento de um pensamento crítico autônomo a partir das ferramentas do letramento midiático, e diversas experiências pelo mundo o demostram. Sempre observando-se os públicos e suas demandas e considerando que, como salienta o documento do Center for Media Literacy (CML, 1989), o letramento midiático não se destina a construir uma "proteção" para crianças e adolescentes, livrando-as de conteúdos danosos. A busca é e deve ser sempre pelo desenvolvimento de uma autonomia crítica. Sem essa autonomia, aponta o CML, "um indivíduo não pode ter plena dignidade como pessoa humana ou exercer a cidadania em uma sociedade democrática, onde ser cidadão é compreender e contribuir para os debates da época [...]”.

Nesse sentido, o estímulo ao questionamento, por exemplo, é uma dessas ferramentas ou estratégias fundamentais. Pode-se instigar os alunos, em relação à estrutura do conteúdo midiático, a fazerem questionamentos, a desenvolverem questões críticas, tais como: quem é a fonte dessa notícia? Quem é o autor da mensagem? Como os grupos midiáticos obtêm dinheiro, recursos? Como os estereótipos são construídos nas mensagens? Quais pontos de vista ou valores estão explicitados ou ocultos nos vários textos e produtos midiáticos?

Ao acompanhar uma atividade da ONG EVC, em New 
York, em 2019, pude ver o desenvolvimento de um trabalho com alunos do Ensino Médio (High School) a partir das discussões e problematizações colocadas pelo letramento midiático. Os estudantes definiram um tema - racismo - e foram a campo, em seu bairro (Bronx), para produzirem notícias da comunidade para um site (construído por eles), a partir de vídeos pelo celular. Com o material apurado e produzido, eles então compararam essas notícias com outras produzidas pelos jornais locais relativas ao tema racismo, discutindo em sala a construção de representações, o viés, os modos de dizer envolvidos nas notícias.

\section{Considerações finais}

Num cenário de desinformação agravado pela desinfodemia, cujo vetor no Brasil foram também agentes públicos, a educação em mídia, o letramento midiático e informacional, é uma prática essencial. Ela contribui para a formação de cidadãos críticos e, desse modo, para a própria consolidação de processos democráticos. Portanto, o desenvolvimento de um projeto sistemático de letramento midiático no Brasil é de grande relevância para o bem-estar social do país, sobretudo em vista do recente processo eleitoral e da eleição de um governo de extrema direita com viés autoritário, que culminou recentemente no processo de desinfodemia que vivenciamos. Sem informação de qualidade, sendo açodada por processos sistemáticos de desinformação, a sociedade fica à mercê de processos não democráticos e de estruturas totalitárias, além de colocar em risco sua própria saúde e a saúde coletiva.

Assim, o desenvolvimento das ferramentas de letramento midiático e informacional promove a cidadania na medida em 
Desinformação, desinfodemia e letramento midiático e informacional - um estudo do processo estruturado no Brasil sob o governo Jair Bolsonaro e as formas de enfrentamento

que auxilia os cidadãos a construirem um posicionamento crítico. Além disso, as ferramentas de letramento midiático são capazes de produzir um engajamento da juventude em relação ao cenário político, contribuindo sobremaneira para o fortalecimento da democracia.

Como salientam Share, Mamikonyan e Lopez:

A democracia na era digital de "notícias falsas" e "fatos alternativos" requer novas habilidades de alfabetização e consciência crítica para ler, escrever e usar a mídia e a tecnologia para fortalecer a participação cívica e a transformação social. ( SHARE, MAMIKONYAN E LOPEZ (2019, p. 20)

Com o crescente acesso dos brasileiros às mídias digitais, entendemos que o letramento midiático informacional pode ser relevante também para a construção efetiva de novos hábitos de promoção de bem-estar e saúde, o que auxiliará no controle da pandemia, na promoção de uma melhor qualidade de vida para toda a sociedade e em melhor interlocução entre academia e sociedade.

\section{Referências}

ALCOTT, Hunt; GENTZKOV, Matthew. Social Media and Fake News in the 2016 Election. Journal of Economic Perspectives, Journal of Economic Perspectives - v. 31, n. 2, p. 211-236, 2017. CARLSSON, Ulla. Understanding Media and Information Literacy (MIL) in the Digital Age. A question of Democracy. Sweden: University of Gothenburg, 2019.

8 Nossa tradução para: "Democracy in the digital networked age of 'fake news' and 'alternative facts' requires new literacy skills and critical awareness to read, write, and use media and technology to empower civic participation and social transformation.". 
FUNDAÇÃO OSWALDO CRUZ. Gerência Regional de Brasília. Fake news e saúde. Brasília: Fiocruz Brasília, 2020. $228 \mathrm{p}$.

HALL, Stuart, et. al. The Social Production of News. Media Studies: A Reader. New York: New York University Press, 2000. HOBBS, Renee; JENSEN, Amy. Past, present and Future of Media Literacy Education. Journal of Media Literacy Education, n. 1, p. 1-11, 2009.

HOBBS, Renee. Media Literacy. Oxford Research Encyclopedia of Communication. Disponível em: https://oxfordre.com/communication/view/10.1093/ acrefore/ $9780190228613.001 .0001 /$ acrefore9780190228613-e-11. Acesso em: 26 jun. 2021.

JENKINGS, Henry. Building the field of digital media Confronting the Challenges of participatory culture: media education for the $21^{\text {st }}$ century. Chicago, USA: MacArthur Foundation, 2006

MASTERMAN, Len. Teaching the Media. London: Routledge, 1985.

MEDIA OWNERSHIP MONITOR BRAZIL. Disponível em: https://brazil.mom-rsf.org/br/midia/

POSETTI, Julie; BONTCHEVA, Kalina. Disinfodemic: Deciphering COVID-19 disinformation. Paris: United Nations Educational, Scientific and Cultural Organization, 2020.

SHARE, J.; MAMIKONYAN, T.; Lopez, E. Critical media literacy in teacher education, theory, and practice. In: Oxford Research Encyclopedia of Education. Oxford University Press. Disponível em: http://dx.doi.org/10.1093/ acrefore/9780190264093.013.1404. Acesso em: 24 jun. 2021.

THOMANN, Elizabeth; JOLLS, Tessa. Literacy for the 21st Century An Overview \& Orientation Guide to Media Literacy Education. Center for Media Literacy, 2002. 
Desinformação, desinfodemia e letramento midiático e informacional - um estudo do processo estruturado no Brasil sob o governo Jair Bolsonaro e as formas de enfrentamento

TIMBERG, Craig. Fake-news ecosystem still thrives, two years after the 2016 election, new report says. The Washington Post, October, 2018. Disponível em: https:// www.washingtonpost.com/technology/2018/10/04/fake-newsecosystem-still-thrives-two-years-after-election-new-reportsays/?utm_source=headtopics\&utm_medium=news\&utm campaign $=2018-10-04$. Acesso em: 2 set. 2021

UNESCO. Jornalismo, Fake News e Desinformação. Manual para Educação e Treinamento em Jornalismo - Série UNESCO sobre Educação em Jornalismo. São Paulo: Unesco, 2019.

WARDLE, Claire. First draft's essential guide to Understanding Information Disorder. First Draft, October, 2019.

WILSON, C et al. Alfabetização midiática e informacional: currículo para formação de professores. Brasília: UNESCO, UFTM, 2013. 